\title{
The Impact of Transformational Leadership on the Self- Creative Efficacy and Intrinsic Motivation in FINTECH Organizations
}

\author{
Dr. Jack D. Torres Leandro ${ }^{1}$ and Dr. Mauricio Vladimir Umana ${ }^{2}$ \\ ${ }^{1}$ Professor of Universidad Estatal a Distancia of Costa Rica \\ ${ }^{2}$ Professor and Researcher at Universidad Católica de El Salvador, El Salvador \\ *Correspondence: Dr. Jack D. Torres Leandro, jtorres1@uned.ac.cr, $+(506) 88256641$
}

\begin{abstract}
The generation of innovation initiatives within companies is a preponderant share for the development and growth of business lines, as it helps to improve the market shares and competitiveness since these come to be implemented and the FINTECH organizations are no exception. However, some companies have not encouraged these dynamic works, hence the need to identify which elements and type of workers contribute to generate these actions.

To do this, it becomes necessary to analyze how transformational leadership, self-creative efficacy, and intrinsic motivation within organizations are given and how with these characteristic's companies create value. Even from the literature review, it was identified that the so-called theory of dynamic capabilities provides a framework to understand that organizations constantly must evolve their resources if they wish to remain competitive in industries that have participation.

To address the above, it seeks to understand the characteristics, abilities, and motivations from transformational leadership to flourish creativity. In this sense, it should be noted that transformational leadership has been conceived as the ability to influence employees by expanding and raising their expectations by giving them confidence to develop beyond their own expectations (Dvir, Eden, Avolio \& Shamir, 2002).

In turn, it is intended to generate information needed for decision-making by the different actors involved in this process to facilitate environments to promote efficiency and effectiveness in the delivery of products and / or services seeking to promote intrinsic motivation in followers to generate value to customers.
\end{abstract}

KEYWORDS: Transformational leadership, self-creative efficacy, intrinsic motivation

ARTICLE INFORMATION
Author(s): Dr. Jack D. Torres Leandro and Dr. Mauricio Vladimir Umana
Received: 19 Oct, 2021; Accepted: 19 Nov, 2021; Published: 05 Dec, 2021;
e-ISSN: 2347-4696;
Paper Id: BMN-IJBMR-2021-71;
Citation: doi.org/10.37391/IJBMR.090408
Webpage-link:
https://ijbmr.forexjournal.co.in/archive/volume-9/ijbmr-090408.html

\section{INTRODUCTION}

In this new era, when speaking about banking institutions in terms of efficiency and business, the main advances in the application of digital technology have focused on specific business segments such as loans, payment systems, financial advice and insurance. In these, fintech companies have the potential to reduce the cost of intermediation and expand access to financing for sectors of the population without services and even for less developed countries.

One reason for this efficiency-enhancing feature lies in the potential to help overcome information asymmetries, which are the foundation of the banking business. Similarly, fintech companies have an efficient operational design culture.

Peer-to-peer (P2P) lending platforms provide credit without bank intermediation where individuals and companies invest in small businesses, seeking to connect directly to borrowers and lenders: some allow to choose their interest providers both in loan packages and subsequent products (Vives, 2017).

Over the years it has been suggested that creativity, the generation of new and useful ideas (Amabile, 1996), is of utmost importance for the survival and competitiveness of organizations (for example, George and Zhou, 2002; Oldham and Cummings, 1996; Zhou, 1998). Consequently, they have been driven by the assumption that the creativity of employees is beneficial to the achievement of the strategic objectives of the company. Thus, researchers have devoted significant attention to identifying its antecedents, but have shown much less interest in its effects (Mumford, 2003; Zhou and Shalley, 2008).

Consequently, creativity is recognized as being of utmost importance for organizations insofar as it positively contributes to the labor productivity of employees (Gilson, 2008). Therefore, it is important to determine both the antecedents and the consequences of employee creativity for a better understanding. (Zhou \& Shalley, 2008).

Some researchers believe that employee creativity will flourish when a leader is able to provide transformational leadership (Jaussi and Dionne, 2003; Shin and Zhou, 2003) and when employees present a learning orientation (Redmond, Mumford, and Teach, 1993).

In light of the above, transformational leadership has been defined in the way of influencing employees by broadening and elevating the goals of followers by giving them the confidence to perform beyond the expectations specified in the implicit or explicit exchange agreement in terms of knowledge refers (Dvir, Eden, Avolio and Shamir, 2002: 735).In the other hand, human beings are continually acting on and adapting to their surroundings, therefore, the motivation for these ongoing interactions with the 
environment is referred to intrinsic motivation (Amabile,1993).

We chose transformational leadership and employee intrinsic motivation as predictors of employee creativity because they are both related to actions intended to improve an individual's competence and hence to lead to productivity (Benjamin \& Flynn, 2006; Kruglanski et al., 2000), and intrinsic motivation has been linked to creativity (Amabile \& Gryskiewicz, 1987).

When we arrive here, we will proceed to examine the antecedents of employee creativity with an intrinsic motivation perspective in mind. In addition, we will study it as a mediator for three reasons. First, intrinsic motivation has been found to be a vital "driver" of performance in a variety of task domains (Bandura, 1986).

Based on this brief discussion, our interest in creativity and the specific nature of the domain of self-efficacy (Bandura, 1997), we will examine the self-creative efficacy of employees as the psychological mechanism behind creativity.

Second, studies have documented a positive relationship between self-creative efficacy and creativity (Tierney \& Farmer, 2002, 2004). Finally, we believe that employees' creative self-efficacy will be higher if they are intrinsically motivated when under the influence of transformational leaders.

\section{LITERATURE REVIEW AND HYPOTHESIS}

2.1 Transformational Leadership and Self-creative efficacy Based on what Burns (2003) noted, it is asserted that transformational leadership is required to solve the world's most critical problems, such as global poverty. This type of approach starts from the fact that it comes from the bottom up that is, in many cases, it comes from people who are more grounded in the context in which they are immersed, by hundreds of leaders who are closer to the poor, who will be capable of listening and reacting to their needs, transforming economies within the geographic and political contexts in which they are present.

To understand creativity, several questions must be answered, including how is creative performance different from ordinary performance? What are the most favorable conditions for creative performance? According to Amabile (1996).

Although FINTECH has autonomous entities, that is, they are governed by their own norms and duly standardized procedures, Gilson et al. 2005, indicate that creativity has been described to guarantee that organizations remain flexible and are able to successfully manage their ever-changing environment.

Therefore, the process can be seen to identify problems or needs using thought, developing hypotheses, communicating ideas to others, and contradicting what could normally be expected, reducing levels of uncertainty and work stress.

Baer (2011) states that ideas are unnecessary unless they are used. The lack of systematic attention is especially surprising given that innovation, particularly in dynamic contexts, is widely recognized as critical to growing competitiveness within organizations.

Consequently, transformational leadership becomes fundamental in this process, especially since it involves aspects that promote creativity within collaborators, such as its intellectual stimulation trait.

By promoting intellectual stimulation, inherently throughout the organization a flow of ideas is generated, which must be facilitated by both formal and informal leaders of the organizations, which serves as a catalyst for timely decision making.

Andriopoulos, (2001) stated that the autonomy that could be derived from these information processes strengthens the empowerment of collaborators for the healthy running of projects and initiatives that could result in creative processes as appropriate.

Wang et al., (2005) established that transformational leaders encourage followers to internalize and prioritize a collective cause over individual interests, therefore, performance levels increase significantly.

Thus, by fostering high levels of trust, positive affection, respect, and loyalty from their respective members; they constitute favorable results in performance as appropriate. The above, as stated by Amabile (1998), “... creativity will be reflected in the passion (seen as motivation) of the collaborators to create unusual ideas..."

In this sense, the following hypothesis is presented:

H1: Transformational leadership has a direct impact on self-creative efficacy.

\subsection{Transformational Leadership and Intrinsic Motivation} The transformational leader of an organization sets beliefs, initiatives, and the appropriate environment to encourage innovation, becoming a self-confident follower, which in turn, leads to the evolution of followers, according to Gumusluoglu et al. 2009.

It is not a coincidence that transformational leaders who care about the feelings and needs of their employees, facilitate the development of their skills, showing them ways to achieve the proposed goals and failing that to reaffirm confidence in themselves visualizing the improvement of productivity in all areas of the organization.

After this digression, Csikszentmihalyi (1988) asserts that however, the original one may be, if one gets bored with an activity, it will be difficult to become interested enough in it to make a creative contribution. Similarly, Amabile (1988) states that a necessary component of intrinsic motivation is the level of enthusiasm of the employee for the activity.

It follows that intrinsic motivation has been cited as one of the most outstanding personal qualities for improving creativity, because it affects an employee's decision to initiate and maintain creative effort over time (Amabile, 1983, 1988).

That is why motivational orientation can be partially configured by the environment (Amabile, 1983), in turn there is evidence that suggests a stable characteristic nature (for example, Amabile, Hill, Hennessey and Tighe, 1994).

As examples of the above, in the cognitive style, 
support for the intrinsic motivation-creativity link has been generated in laboratory settings, among student samples, or using self-report creativity measures (for example, Amabile, 1985; Amabile, et al.1994).

Oldham and Cummings (1996) emphasized the role of intrinsic motivation as a mechanism by which the proposed contextual factors would operate on creativity; the level of real intrinsic motivation of the employees was not included as a study variable.

Based on this maxim, self-development is one of the primary characteristics of transformational leaders. This is because they directly affect their collaborators for their natural evolution from a status quo, being able to promote in them an intellectual stimulation that ultimately generates organizational innovation within the FINTECH organizations.

As stated by Jung et al. 2003, transformational leaders go beyond praising contractual agreements to achieve the desired performance by actively linking followers within their personal value systems.

These provide ideological explanations that link followers in the mission and vision of the organization. Transformational leaders increase the understanding and values associated with the expected results, increase their performance expectations, and increase their willingness to transcend their own interests for the good of the collective entity.

Having said that, it refers to the motivational state in which collaborators are attracted and energized by their own task instead of the external results that it could lead to. Intrinsically, motivated employees tend to be more cognitive, flexible, and persistent.

In this sense, collaborators are generally more eloquent, finding many meanings to solve problems, using non-traditional approaches and at the same time being persistent. The elements discussed above suggest that individuals can exhibit high levels of creativity (Shin et al., 2003, Scott et al., 1994).

According to Jenssen et al. 2004, it will be taken for granted that a transformational leader refers to an individual who is willing to take risks, enthusiastically promoting the development and / or implementation of an innovation within a company through a process of acquiring resources. The definition shows how these types of individuals have the necessary drive and character embedded within their DNA to see an idea materialize within an organization.

Human beings and their organizations have often been designed to focus on protecting the existing practices as opposed to focusing on new directions. The foregoing, because people have psychological limitations of not being able to manage complexity, of unconsciously adapting gradually to changing conditions, forming norms, and focusing on repetitive activities (Van de Ven, 1986).

Because intrinsic motivation has been positioned as playing a crucial role in employee creativity, but has not been tested in a field setting, it was considered as one of the key employee characteristics in the current study. Therefore, we present the next hypothesis:

H2: Transformational leadership has a direct impact on intrinsic motivation.

\subsection{Intrinsic Motivation and Self-Creative Efficacy}

Intrinsic motivation is defined as interest and enjoyment in an activity on its own. The feelings of mastery, efficiency, and autonomy are inherent to the intrinsic interest in the task. The intrinsic motivation construct describes the tendency to mastery, spontaneous interest, and exploration that is essential to cognitive and social development and represents the main source of joy and vitality throughout life (Ryan \& Deci, 2000).

Many of the individual's actions that are initially controlled by external events, later become regulated by internal events through an internalization process that generally occurs in several stages (Deci \& Ryan, 1985, Ryan \& Deci, 2000).

Motivation concerns energy, direction, persistence and equifinality--all aspects of activation and intention. Motivation has been a central and perennializing the field of psychology, for it is at the core of biological, cognitive, and social regulation. Perhaps more important, in the real world, motivation is highly valued because of its consequences, Barbuto (2005).

Although motivation is often treated as a singular construct, even superficial reflection suggests that people are moved to act by very different types of factors, with highly varied experiences and consequences.

People can be motivated because they value an activity or because there is strong external coercion. They can behave from a sense of personal commitment to excel or from fear of being surveilled. These contrasts between cases of having internal motivation versus being externally pressured dare surely familiar to everyone, Gilbert, Horsman \& Kelloway (2016).

The issue of whether people stand behind a behavior out of their interests and values, or do it for reasons external to the self, is a matter of significance in every culture (e.g. Johnson, 1993) and represents a basic dimension by which people make sense of their own and others behavior (deCharms, 1968; Heider, 1958; Ryan \& Connell, 1989).

Perhaps no single phenomenon reflects the positive potential of human nature as much as intrinsic motivation, the inherent tendency to seek out novelty and challenges, to extend and exercise one's capacities, to explore, and to learn. Developing mentalists acknowledge that from the time of birth, children, in their healthiest states, are active, inquisitive, curious, and playful, even in the absence of specific rewards (e.g., Harter, 1978).

The construct of intrinsic motivation describes this natural inclination toward assimilation, mastery, spontaneous interest, and exploration that is so essential to cognitive and social development and that represents a principal source of enjoyment and vitality throughout life (Csikszentmihalyi \& Rathunde, 1993; Ryan et al., 1995).

In this way, the orientations, that frame creativity, define it mainly in three lines of work, first, as a process, then as a product, emphasizing the creative person, and third, as a combination of factors.

This approach to the creative process and product is 
explained by Goñi (2000), who indicates that the expression "creative process" could be a sequence of steps or stages used to solve a problem or that it can represent a rapid or perceptual change. The transformation that is available when a new idea or solution to a problem occurs.

However, it can also refer to the techniques or strategies that creative people use, either consciously or unconsciously, to produce a new idea or combination, relationship, meaning, perception, or transformation, Khalili (2016).

Thus, a creative product is a work that is accepted for its usefulness by a group at some point. This acceptance is in the product and not on the process; an example of this is presented with artistic productions that had a process within the individual; but they are considered valuable for the product itself until long after its first presentation, Gumusluoglu, L., \& Ilsev, A. (2009).

For example, Haan \& Havighurst (1961) indicate that creativity is any activity that leads to the production of something new, it can be a technical invention, a new discovery in science or a new artistic achievement.

Regarding to self-creative efficacy is important to understand the orientations that frame creativity defines it mainly in three lines of work. First, as a process, then as a product, emphasizing the creative person, and third, as a combination of factors, Robinson-Walia (2020).

As a complement to this research, other definitions of creativity and creative person have been presented. For example, Haan and Havighurst (1961) indicate that they underlie any activity that leads to the production of something new, and it can be a technical invention, a new discovery in science or a new artistic achievement, influenced by the intrinsic motivation of the human being.

In this sense, we present the following hypothesis:

H3: Intrinsic motivation has a direct impact on selfcreative efficacy

\section{METHODOLOGY}

The present work is based on the approach design and evaluation of a model of structural equations where the relationships between latent variables and measurement variables are represented. Within these latent variables, we want to measure highly complex phenomena, which for our exercise correspond to the transformational leadership, creative-self efficacy, and intrinsic motivation based on validated scales.

In the same way, for the measured variable, which in this case creative-self efficacy, a validated scale will also be used, which will be applied to directly measure the observable characteristics of the phenomenon in depth.

As there is an ever-increasing economic deficit in our current environment, the psychosocial study of the mentioned variables is a line of national research interest to pave the way for FINTECH organizations that can take advantage of the national and international market.

In this sense, to measure of transformational leadership, we used Podsakoff et al. (1990) instrument, related to self-creative efficacy Gong et al. (2009) and finally for the intrinsic motivation Tierney et al. (1999) for the 1200 followers of a FINTECH organization in Latin America.

For its part, once the survey is applied to the participants, the analysis will be carried out to evaluate the areas where followers consider they have the necessary leadership and intrinsic motivation to carry out innovative projects in their respective organization, and from the results it is expected to have enough information to identify areas that require improvement or, failing that, strengthening of competencies as appropriate.

The central objective of this research is to understand how transformational leadership (TL) of the heads influences the creative self-efficacy (CSE) of the followers, moderated by their intrinsic motivation (IM), the latter being the unit of analysis, suggested as a future line of investigation according to Jaiswal \& Dhar (2015) and Gong, Huang \& Farh (2009).

Based on all of the above, to address the subsequent, we present the following research model.

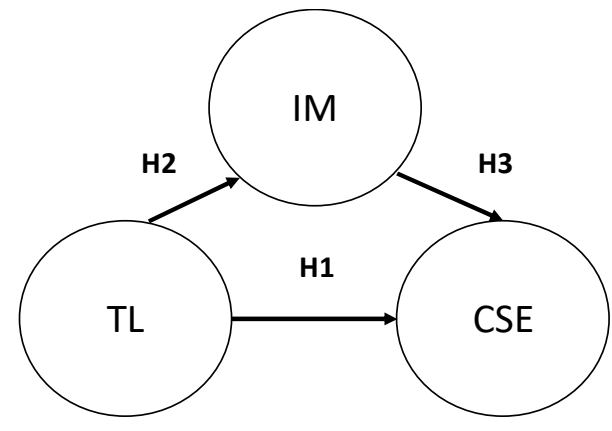

Figure 1: Investigation model (Source: Own elaboration of Dr. Jack D. Torres Leandro)

Taking into consideration the proposed research model, the statistical method of structural equations will seek to show that there is a close relationship with the data model, according to figure 2, using the AMOS program with the three latent variables.

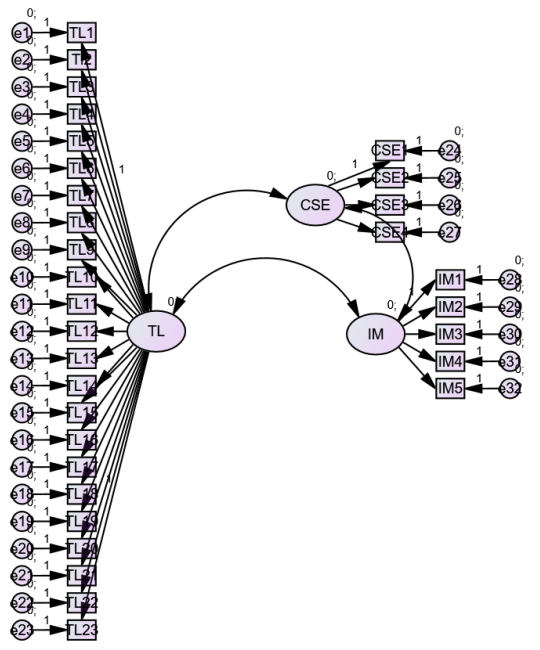

Figure 2: Data model 
(Source: Own elaboration of Dr. Jack D. Torres Leandro)

From the methodological framework, the instrument developed has been adapted according to the scales of: transformational leadership, creative self-efficacy, and intrinsic motivation with a standardized likert scale, which uses as measurement elements: (1) strongly disagree, (2) in disagreement, (3) something in disagreement, (4) Nor agree or disagree, (5) somewhat agree, (6) agree and (7) totally agree.

In the following sections, aspects such as the implementation of the instrument, the selection of the interviewees, and the development of the surveys will be addressed, namely the following:

\section{(a) Implementation of the instrument}

Based on the space provided by FINTECH organization in Latin America, the corresponding survey was implemented during the last quarter of 2020 where the largest number of the target population of our study is found. This study was carried out in Costa Rica with 1,200 people, which shows some solidity in the database obtained.

\section{(b) Random selection of interviewees}

As indicated, the unit of analysis will be the followers of the FINTECH organization in Latin America. At the same time, questionnaires were collected on the last business day of 2020 .

\section{(c) Development of the surveys}

In the FINTECH organization was enabled a website to explain all the population of the company the objective of the current research followed by a personalized email.

It is very important to highlight that the participants completed a questionnaire where, first, information on personal data, such as: gender, age, and work experience, was collected and later on what was related to each of the constructs indicated above.

For this purpose, the following Table 1 shows the distribution of personal data mentioned for gender in the participation of this investigation.

Table 1. Distribution by Gender

\begin{tabular}{|l|c|c|}
\hline \multicolumn{1}{|c|}{ Gender } & Frequency & Percentage (\%) \\
\hline Female & 700 & $58 \%$ \\
\hline Male & 500 & $42 \%$ \\
\hline Total & 1200 & $100 \%$ \\
\hline
\end{tabular}

(Source: Own elaboration)

\section{RESULTS}

When performing the analysis of the consistency of the instrument related to its validity and reliability, a Cronbach's Alpha of 0.948 is obtained for all items. The reliability by internal consistency can be taken as a way of estimating the equivalence of the components among themselves and its estimation will then be an equivalence coefficient calculated from a single application of the test.

However, when reviewing the literature on the subject, an additional procedure was carried out to ensure that the scale was not oversized, due to the high value of Cronbach's Alpha. Based on the above, we proceeded to analyze each of the latent variables with their proper scale to know the internal consistency between each of the items, where the scale of transformational leadership an alpha of 0.910 is shown.

For its part, for creative self-efficacy scale, an alpha of 0.950 is reported. Additionally, regarding the intrinsic motivation scale, an alpha of 0.928 is denoted. Table 2 shows the descriptive statistics of the variables under study (mean, standard deviation, skewness, and kurtosis). As it can be seen, the univariate asymmetry and kurtosis indices were below the value 2, as recommended by Bollen and Long (1993), which indicates similarity with the normal curve.

Table 2. Descriptive statistics

\begin{tabular}{|c|c|c|c|c|}
\hline Latent Variable & Mean & $\begin{array}{c}\text { St. } \\
\text { deviation }\end{array}$ & Skewness & Kurtosis \\
\hline $\begin{array}{c}\text { Transformational } \\
\text { Leadership }\end{array}$ & 4,02 & 0,84 & $-0,49$ & $-0,41$ \\
\hline $\begin{array}{c}\text { Creative Self- } \\
\text { Efficacy }\end{array}$ & 3,86 & 1,06 & $-0,84$ & 0,44 \\
\hline $\begin{array}{c}\text { Intrinsic } \\
\text { Motivation }\end{array}$ & 4,27 & 0,70 & $-0,66$ & 0,21 \\
\hline
\end{tabular}

(Source: Own elaboration)

That is why by contrasting the results in each of the latent variables, it is reflected that the alpha value for the entire instrument is consistent in each of its dimensions.

Taking into consideration the factor analysis carried out, it is shown that the theoretical model is compatible with the data model. For which, the null hypothesis proposed for this research is accepted having a value of $p=0.195$ with a chisquare value of 81.02 and with 71 degrees of freedom. This can be seen in the following standardized data model, according to the results obtained in the AMOS program, as shown in figure 3.

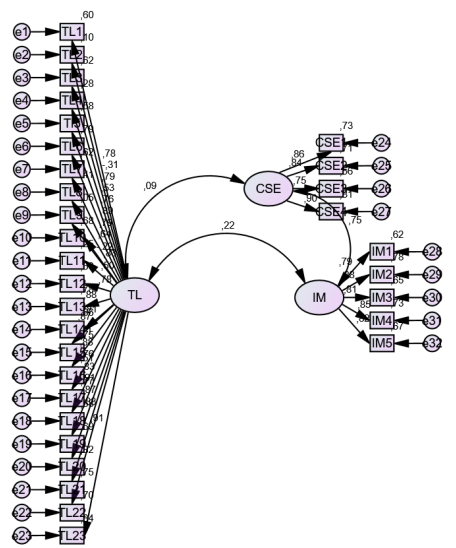

Figure 3: Standardized data model for the impact of transformational leadership on the self-creative efficacy and intrinsic motivation in FINTECH organizations in Latin America

(Source: Own elaboration of Dr. Jack D. Torres Leandro) 
On the other hand, when evaluating the goodness of fit indicators according to the proposed model, the results show that they contain acceptable values, according to the GFI indicators with a value of 0.91 and AGFI with 0.866 as the resulting value. Likewise, it should be noted that there were no standardized factor loads outside the interval.

In relation to the factor analysis carried out, it is considered that it is not necessary to re-pose the theoretical and data model; this is because the results are consistent with the proposed model.

\section{DISCUSSION OF RESULTS AND CONCLUSIONS}

\subsection{Discussion of the Structural Model}

Taking into consideration that analyzes carried out from similar investigations, it is presented as a reference to Nader \& Castro 2007 in their study of the influence of values on leadership styles: an analysis according to Bass's transformational-transactional leadership model, it is concluded that if there is a relationship of people in positions of power exerting motivational influence on the behavior of their subordinates. This conclusion was reached through a path analysis or multiple regression diagram to test the hypotheses, which supports our model that a leader, using his leadership transformational, can motivate its followers towards paths of self-creative efficacy.

In turn, Santoso, Elidjen, Abdinagro et al. 2019 use a structural equations model in their study of the influence of transformational leadership on some variables of organizational performance on creative self-efficacy. They point out among their conclusions that the support positive and significant relationship between transformational leadership and self-creative efficacy generate an increase in followers' satisfaction and intrinsic motivation in changing their beliefs, attitudes and business skills.

In a similar work by Hung, Huang \& Lin (2008), where the structural equations model was used to measure the influence of intrinsic motivation and self-creative efficacy in followers, is identified that there is empirical evidence to support the hypothesis that the intrinsic motivation in followers has a positive effect in the self-creative efficacy in a significant way.

\subsection{Discussion of the Measurement Model}

This study is conclusive that the model presented explains the coincidence that exists between transformational leadership and its impact on self-creative efficacy moderated by intrinsic motivation. In this sense, Table 3 shows the hypothesis statement and its respective relationship according to the variables of the structural model, together with the standardized beta values for each case as appropriate.
Table 3. Structural Model Analysis

\begin{tabular}{lllll}
\hline Hypothesis & Standardized Beta & \multicolumn{2}{c}{ t Value } \\
\hline $\mathrm{H}_{1}$ Transformational Leadership & $\longrightarrow$ & Self-creative efficacy & 0.330 & 3.040 \\
$\mathrm{H}_{2}$ Transformational Leadership $\longrightarrow$ & Intrinsic Motivation & 0.439 & $9.841^{* * *}$ \\
$\mathrm{H}_{3}$ Intrinsic Motivation $\longrightarrow$ & Self-creative efficacy & 0.064 & $0.897^{*}$
\end{tabular}

S-B $\mathrm{X}^{2}(72 \mathrm{gl})=87,98 ; \mathrm{p}>0.05 ; \mathrm{RMSEA}=0.042 ; \mathrm{CFI}=0.880 ;{ }^{* * *} \mathrm{p}<0.01 ;{ }^{*} \mathrm{p}<0.05$ (Source: Own elaboration of Dr. Jack D. Torres Leandro)

Based on the above, we proceed to interpret each of the hypotheses:

5.2.1 The importance of Transformational Leadership on Self-Creative Efficacy

$\mathrm{H} 1$ is maintained; the transformational leadership of leaders significantly influence on self-creative efficacy of followers.

This hypothesis is consistent with the work of Baer (2011) in the sense that ideas promote growth from a leadership that manages to promote them, in this case, the transformational type is evidence of the future, especially in contexts where uncertainty and volatility are part of the new normal.

In this manner, transformational leadership is of special importance because it promotes the intellectual trait in collaborators encouraging them to visualize horizons beyond their own organizations.

Consequently, by promoting intellectual stimulation, the flow of ideas by the collaborators begins to emerge as part of the organizational dynamic becoming in some cases a decisive factor for decision-making as appropriate.

In accordance with the above, within the organizational culture, employees find safe psychological spaces that allow them to raise ideas that catalyze the development of projects for the fulfillment of business objectives as appropriate.

After this brief disagreement, a necessary particularity to highlight, transformational leadership fosters in collaborators the ability to seek common agreements in which the sum of knowledge is visualized and with it the generation of possible sources of competitive advantages.

\subsubsection{The Importance of Transformational Leadership on Intrinsic Motivation}

$\mathrm{H} 2$ is maintained; transformational leadership positively and significantly affects intrinsic motivation of followers.

On the other hand, based on hypothesis 2, it is evidenced that transformational leadership has a positive impact on employees within FINTECH. This beings an impulse to increase the confidence or security of employees, 
positively affecting their performance.

Inevitably, transformational leadership is a type of leadership that inspires employees to prioritize and focus their efforts when carrying out their daily activities, paying special attention to the awareness of employees in changing the mentality of solving the challenges that arise looking for new options to achieve them.

The interaction between leaders and employees is characterized by the influence of changing operating behavior so that they feel capable and highly motivated to achieve optimal levels of performance and quality from a joint vision.

\subsubsection{The Importance of Intrinsic Motivation on Self- Creative Efficacy}

H3 is maintained; the intrinsic motivation positively affects the self-creative efficacy of followers.

Regarding hypothesis 3 , creativity is recognized as a behavioral construct by virtue of the fact that it encourages the generation of novel and useful ideas, which by having organizational spaces to develop them triggers the intrinsic motivation of each one.

This is how this hypothesis confirmation allows us to understand one of the fundamentals that promotes creativity within organizations, especially in FINTECH, this being one of the necessary sectors of the economy for nations in times of post-pandemic.

Intrinsic motivation refers to the degree to which people engage in an activity mainly because they find the activity itself interesting, enjoyable, and challenging since it is closely related to creative self-efficacy while recognizing it as a belief in oneself. That one has the ability to produce creative results, the main desire being to contribute to the collective well-being.

\section{PRACTICAL IMPLICATIONS OF PUBLIC POLICY}

This study was carried out in Latin America, however, it has applications to other countries and regions worldwide because we are in a time of leadership crisis faced by countries in all spheres. These results demand more research on the type of transformational leadership that we need to positively influence and motivate the structural changes demanded by today's society.

The current world is in crisis due to the COVID-19 Pandemic which is endemic, the climate, the social, environmental and economic sustainability crisis that we all face every day. This type of leadership that influences, motivates, and makes things happen is needed by companies, by governments, by NGOs, and by citizens.

Based on Hypothesis 1: the transformational leadership of leaders significantly influences on self-creative efficacy of followers. If our governors, businessman, and community leaders had this transformational leadership, not necessarily in all cases, but in much of the analysis, we could create a society in which projects are materialized because the creativity and effectiveness of the leader's followers show commitment. This is much needed in Latin America because that transformation of leaders is needed by forming more and more effective and independent leaders of a political party, an ideological current, or a commitment to third parties. These are the leaderships for the society of tomorrow.

Based on Hypothesis 2: transformational leadership positively and significantly affects intrinsic motivation of followers. This is very understandable in the power ambiance of companies and countries, and has very important implications for leadership roles at the institutional level or even for transnational companies; people work for wages, but require other types of psychological wages, to achieve motivation.

A company without motivation goes adrift, a political institute without a clear direction for motivation moves to any edge and an NGO that has a social purpose, without intrinsic motivation, would never achieve its indicators. To be companies and societies that are constantly learning and innovating, we need that motivation to go that extra mile, and this is impossible if the fuel of transformational leadership is not nearby.

It is easy to understand why companies fail, why the results are not given in municipal management, why the government works reluctantly, and why we are not knowledge societies. It is because there is no motivation for both employees and citizens in general and here the presidents of companies and community leaders, mayors and presidents of nations have a large part of that responsibility.

Based on Hypothesis 3: The intrinsic motivation positively affects the self-creative efficacy of followers. This is tangible when companies are studied at the microeconomic level or territories or regions at the macroeconomic level. Probably, that blood that makes ideas flow and translate into concrete results is motivation, therefore, as the objective is the achievement of the result, the realization of the goal, becomes effective.

Along the same lines of argument, we can notice how peaceful demonstrations in certain regions, at the level of example, on environmental issues, have their metaphors and intrinsic motivation in the leaders of the crowd. They make any number of communications and gestures that allow guiding the group until people take a certain level of independence and begin to create ideas, propose solutions, and many of them are executed and others manage to be effective in persuading the citizen what they want to convince.

At the business level, intrinsic motivation is also vital to achieve the levels of creativity and efficiency required by the different strategic business units. It must be effective, but it can be at risk of the person or even if it is effective, it can put the continuity of the business at risk.

Based on analysis, this way of working in transformational leadership can present the guidelines for leaders that we really need to be more and more, societies that can embrace new technologies, new knowledge and the new way of doing business with all the opportunities that technological innovations and Fintech companies offer for today's world. 


\section{FUTURE RESEARCH}

This research shows that promoting one's own creativity depends on a great extent on being able to maintain intrinsic motivation; involving focusing on doing what you love. In this regard, an issue to assess is finding a job that matches the experience acquired over time, skills to promote creative thinking, and their respective intrinsic motivations.

In this sense, it could be interesting to measure other types of leadership like authentic leadership, servant leadership, digital leadership among others.

In addition to this, the organizational culture is very important that allows to retain a motivational approach for the exploration and development of new ideas. As Managers manage to learn these particularities, they will be able to better channel the recruitment and selection processes of future collaborators and thereby minimize the obstacles that foster creativity and with it the development of portfolios of improved products and services for organizations FINTECH in view of its speed of penetration to the market.

Acknowledgement: To Veronica Cruz for professional translation of this academic work.

\section{REFERENCES}

[1] Andriopoulos, C. (2001). Determinants of organisational creativity: a literature review. Management decision.

[2] Amabile, T. M. (1983). The social psychology of creativity: A componential conceptualization. Journal of personality and social psychology, 45(2), 357.

[3] Amabile, T. M. (1985). Motivation and creativity: Effects of motivational orientation on creative writers. Journal of personality and social psychology, 48(2), 393.

[4] Amabile, T. M. (1988). From individual creativity to organizational innovation.

[5] Amabile, T. M. (1993). Motivational synergy: Toward new conceptualizations of intrinsic and extrinsic motivation in the workplace. Human resource management review, 3(3), 185-201.

[6] Amabile, T. M. (1996). Creatividad e innovación en las organizaciones. Harvard business school, 305-S11.

[7] Amabile, T. M. (1998). How to kill creativity (Vol. 87). Boston, MA: Harvard Business School Publishing.

[8] Amabile, T. M., Hill, K. G., Hennessey, B. A., \& Tighe, E. M. (1994). The Work Preference Inventory: assessing intrinsic and extrinsic motivational orientations. Journal of personality and social psychology, 66(5), 950.

[9] Amabile, T., \& Gryskiewicz, S. S. (1987). Creativity in the $R \& D$ laboratory. Center for Creative Leadership.

[10] Baer, R. A. (2011). Measuring mindfulness. Contemporary Buddhism, 12(1), 241-261.

[11] Bandura, A. (1986). The explanatory and predictive scope of self-efficacy theory. Journal of social and clinical psychology, 4(3), 359-373.

[12] Bandura, A. (1997). Self-efficacy: The exercise of control. New York: Freeman.

[13] Barbuto Jr, J. E. (2005). Motivation and transactional, charismatic, and transformational leadership: A test of antecedents. Journal of Leadership \& Organizational Studies, 11(4), 26-40.

[14] Benjamin, L., \& Flynn, F. J. (2006). Leadership style and regulatory mode: Value from fit?. Organizational Behavior and Human Decision Processes, 100(2), 216-230.

[15] Csikszentmihalyi, M. (1988). Motivation and creativity: Toward a synthesis of structural and energistic approaches to cognition. New Ideas in psychology, 6(2), 159-176.

[16] Csikszentmihalyi, M., \& Rathunde, K. (1993). The measurement of flow in everyday life: toward a theory of emergent motivation.

[17] DeHaan, R. F., \& Havighurst, R. J. (1961). Educating gifted children. Chicago: University.

[18] Deci, E. L., \& Ryan, R. M. (1985). The general causality orientations scale: Self-determination in personality. Journal of research in personality, 19(2), 109-134.

[19] Decharms, R., \& Carpenter, V. (1968). Measuring motivation in culturally disadvantaged school children. The Journal of Experimental Education, 37(1), 31-41.

[20] Dvir, T., Eden, D., Avolio, B. J., \& Shamir, B. (2002). Impact of transformational leadership on follower development and performance: A field experiment. Academy of management journal, 45(4), 735-744.

[21] George, J. M., \& Zhou, J. (2002). Understanding when bad moods foster creativity and good ones don't: the role of context and clarity of feelings. Journal of applied psychology, 87(4), 687.

[22] Gilbert, S., Horsman, P., \& Kelloway, E. K. (2016). The motivation for transformational leadership scale: An examination of the factor structure and initial tests. Leadership \& Organization Development Journal.

[23] Gilson, L., \& Raphaely, N. (2008). The terrain of health policy analysis in low and middle income countries: a review of published literature 1994-2007. Health policy and planning, 23(5), 294-307.

[24] Gilson, L. L., Mathieu, J. E., Shalley, C. E., \& Ruddy, T. M. (2005). Creativity and standardization: complementary or conflicting drivers of team effectiveness?.Academy of Management journal, 48(3), 521-531.

[25] Gong, Y., Huang, J. C., \& Farh, J. L. (2009). Employee learning orientation, transformational leadership, and employee creativity: The mediating role of employee creative selfefficacy. Academy of management Journal, 52(4), 765-778.

[26] Goñi, E., \& Infante, G. (2010). Actividad físico-deportiva, autoconcepto físico y satisfacción con la vida. European journal of Education and Psychology, 3(2), 199-208.

[27] Gumusluoglu, L., \& Ilsev, A. (2009). Transformational leadership, creativity, and organizational innovation. Journal of Business Research, 62(4), 461-473.

[28] Harter, S. (1978). Effectance motivation reconsidered. Toward a developmental model. Human development, 21(1), 34-64.

[29] Heider, F. (1958). The naive analysis of action.

[30] Hung, S. P., Huang, H. Y., \& Lin, S. S. (2008). Do significant others' feedback influence one's creative Bhavior?-Using structural equation modeling to examine creativity self-efficacy and creativity motivation mediation effect.Bulletin of Educational Psychology.

[31] Jaiswal, N. K., \& Dhar, R. L. (2015). Transformational leadership, innovation climate, creative self-efficacy and 
employee creativity: A multilevel study. International Journal of Hospitality Management, 51, 30-41.

[32] Jaussi, K. S., \& Dionne, S. D. (2003). Leading for creativity: The role of unconventional leader behavior. The Leadership Quarterly, 14(4-5), 475-498.

[33] Jenssen, J. I., \& Jørgensen, G. (2004). How Do Corporate Champions Promote Innovations? International Journal of Innovation Management, 08(01), 63-86.

[34] Jung, D. I., Chow, C., \& Wu, A. (2003). The role of transformational leadership in enhancing organizational innovation: Hypotheses and some preliminary findings. The Leadership Quarterly, 14(4), 525-544.

[35] Khalili, A. (2016). Linking transformational leadership, creativity, innovation, and innovation-supportive climate. Management Decision.

[36] Kruglanski, A. W., Thompson, E. P., Higgins, E. T., Atash, M., Pierro, A., Shah, J. Y., \& Spiegel, S. (2000). To" do the right thing" or to" just do it": locomotion and assessment as distinct self-regulatory imperatives. Journal of personality and social psychology, 79(5), 793.

[37] MacGregor Burns, J. (2003). Transforming leadership. New York, NY: Atlantic Monthly.

[38] Mumford, M. D. (2003). Where have we been, where are we going? Taking stock in creativity research. Creativity research journal, 15(2-3), 107-120.

[39] Oldham, G. R., \& Cummings, A. (1996). Employee creativity: Personal and contextual factors at work. Academy of management journal, 39(3), 607-634.

[40] Podsakoff, P. M., MacKenzie, S. B., Moorman, R. H., \& Fetter, R. (1990). Transformational leader behaviors and their effects on followers' trust in leader, satisfaction, and organizational citizenship behaviors. The leadership quarterly, 1(2), 107-142.

[41] Robinson-Walia, S. (2020). The Relationship Between Transformational Leadership, Leader Creativity, and Leader Personality (Doctoral dissertation, Grand Canyon University).

[42] Redmond, M. R., Mumford, M. D., \& Teach, R. (1993). Putting creativity to work: Effects of leader behavior on subordinate creativity. Organizational behavior and human decision processes, 55(1), 120-151.

[43] Ryan, R. M., \& Connell, J. P. (1989). Perceived locus of causality and internalization: examining reasons for acting in two domains. Journal of personality and social psychology, 57(5), 749.

[44] Ryan, R. M., Deci, E. L., \& Grolnick, W. S. (1995). Autonomy, relatedness, and the self: Their relation to development and psychopathology.

[45] Ryan, R. M., \& Deci, E. L. (2000). Intrinsic and extrinsic motivations: Classic definitions and new directions. Contemporary educational psychology, 25(1), 54-67.

[46] Santoso, H., Elidjen, E., Abdinagoro, S., \& Arief, M. (2019). The role of creative self-efficacy, transformational leadership, and digital literacy in supporting performance through innovative work behavior: Evidence from telecommunications industry. Management Science Letters, 9(13), 2305-2314.

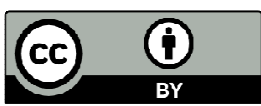

(C) 2021 by the Dr. Jack D. Torres Leandro and Dr. Mauricio Vladimir Umana. Submitted for possible open access publication under the terms and conditions of the Creative Commons $\begin{array}{llll}\text { Attribution } & (\mathrm{CC} & \mathrm{BY}) & \text { license }\end{array}$ (http://creativecommons.org/licenses/by/4.0/). 